\title{
The Factors Influencing the Buying Decision of Customers Behaviour
}

\author{
ALEŠ LUKMAN \\ Gvo d.o.o., Slovenia \\ ales.lukman@siol.net \\ TINA VUKASOVIĆ \\ University of Primorska, Slovenia \\ tina.vukasovic@upr.si
}

The topic of the paper is the analysis of the factors influencing the buying decision of consumer behaviour when buying fixed telecommunications connections. Telecommunications is an area that deals with the transmission of information between distant locations. Its development has been exponential in recent decades and today it represents one of the key factors in the formation of society. The objective of this research is to better understand consumers' behaviour toward fixed telecommunications connections in selected European country. The method used for data collection was a structured online questionnaire. Results indicated that $90 \%$ of respondents are satisfied with the provider of fixed telecommunications connections. The most important factor in a customer's purchasing decision is the characteristics of the telecommunication connector. The second one is brand. The results of the research could be used for planning further marketing activities and marketing strategies in the telecommunications companies and related industries.

Key words: consumer behaviour, purchase decision, factors, service marketing, telecommunications

\section{Introduction}

The evaluation of marketing concept from mere selling concept to consumer oriented marketing has resulted in buyer behaviour becoming an independent discipline. Consumer Behaviour is the study of how individuals make decision to spend their available resources (time, money and effort) on consumption related aspects. It is the study of when, why, how, where and what people do or do not buy products. It blends elements from psychology, sociology, social psychology, anthropology \& economics. It attempts to understand the influencing factors of a customer purchase decision making process, both individually and in groups by understanding his demographics 
and behavioural variables, influences on the consumer from groups such as family, friends, reference groups, and society in general (Sethi 2018).

During the process of purchase decision-making, consumer behaviour is affected by various factors. These can be divided into several factor (influence) groups: psychological (motivation, attitude, learning and memory), social (reference groups, family, individual's role and position, status), personal (age and level of a family's life cycle, occupation and financial situation, lifestyle, personality and self-image, values and beliefs), cultural (culture, social class), economic (price - monetary and non-monetary aspect, income, quality), situational factors related to time and place of purchase (physical environment such as store, location, equipment; social environment as salesperson's influence, time associated with seasonal influences, days of the week and previous consumer mood), individual differences and environmental impacts (Habjanič and Ušaj 2003; Blackwell, Miniard, and Engel 2006; Azevedo et al. 2008; Bennett 2011; Prodnik 2011; Kotler and Armstrong 2018; Vukasović 2020). These factors cause consumers to develop product and brand preferences. Although many of these factors cannot be directly controlled by marketers, understanding of their impact is essential as marketing mix strategies can be developed to appeal to the preferences of the target market (Rani 2014).

In telecommunication business, there are several variable there are used in order to attract customer to buy service. The variable are how brand image (Srinuan, Srinuan, and Bohlin 2014; Ashaduzzaman, Ahmed, and Khan 2011), how tariff and promotion from service provider (Karacuka, Catık, and Haucap 2012; Ashaduzzaman, Ahmed, and Khan 2011; Confraria, Ribeiro, and Vasconcelos 2017; Srinuan, Srinuan, and Bohlin 2014). Network is also influence customer behavior while choose service provider. The previous studies define that network also effect customer choice. From the study of Kotler (1997), relation can affect buying behavior. Several service providers have special offering for similarity provider. Qi et al. (2015) and Confraria, Ribeiro, and Vasconcelos (2017) define that relation has influence for buying behavior. Distribution is an activity to facilitate the consumer to get the services delivered. Choosing the right path will make it easier for consumers to obtain existing services (Hidayati, Ginting, and Nasution 2018). The characteristics of the salesperson and the telecommunication company also play a very important part in the buying decision of consumers in the sale of fixed telecommunications connections. Companies should, 
therefore, have better knowledge of consumers than in the past. For the successful realization of a sales transaction it is necessary for the sales person to know a number of different factors that influence the purchase decisions of users or customers. The salespeople are required to possess knowledge of the market environment where the interaction takes place. The knowledge of buyers' buying habits and influencers in the purchasing decisions is also required. In the context of cultural factors, salespeople have to be aware of or be able to identify and respect the customer's core values and norms. In the context of social factors, the salespeople have to primarily recognize the influence of traditional values, reference groups and family in the purchase behaviour. The salesperson has to identify, in the context of the buyer's personal factors, the need based on the buyer's life cycle, the financial situation and the characteristics of the products the buyer is purchasing. Within the psychological factor, however, it is important to identify a motive that encourages the buyer to make a purchasing decision. Price is certainly a factor that shapes the customer's perception of the quality of the service, and the individual needs of the customers also have to be taken into account.

By designing its marketing strategy, the company shapes the characteristics of the company that play an important role in consumer buying decisions. In today's competitive environment, markets are increasingly saturated with brands and the battle for (possibly loyal) consumers is increasingly fierce. This is particularly noticeable in the telecommunications industry, as its elements are changing even faster than in other industries, which means that the battle for the consumer is even fiercer and, therefore, the processes of developing and adapting to competitors and the market situation need to take place even faster. In this day and age of increasing pressure of information and marketing on consumers, brands are the cornerstones of quality, consistency and trust (Kapferer 2008). The brand is the transmitter of information about the quality, tradition, style, status, manufacturer and origin of the product. According to Konečnik Ruzzier $(2011,159)$, the function of a company's brand has the following characteristics from the user's point of view: facilitates product recognition from competing products, enables better transparency and access to information on the market, facilitates price comparisons, ensures product quality, ensures better sales services, makes it easier to buy, reduces the sense of risk. In this paper, an important feature of the company is represented also by the characteristics of telecommunication connection as the central entity of the service and its after-sales activities. 